\title{
Evaluation of volumetric bone loss during osteotomy between crestal implant and basal implant before implant placement
}

\author{
Ajay k Pillai ${ }^{*}$, Shaji Thomas ${ }^{2}$, Ruchir Dubey ${ }^{3}$ and Neha Jain ${ }^{4}$ \\ ${ }^{1}$ Professor \& HOD, Department of Oral \& Maxillofacial Surgery, People's Dental Academy, Peoples University, Bhopal, Madhya Pradesh, India \\ ${ }^{2}$ Professor and HOD, Department of Oral \& Maxillofacial Surgery, People’s College of Dental Sciences \& Research Center, Peoples University, Bhopal, Madhya \\ Pradesh, India \\ ${ }^{3}$ Consultant, Oral \& Maxillofacial Surgeon, Bhopal, Madhya Pradesh, India \\ ${ }^{4}$ Reader, Department of Oral \& Maxillofacial Surgery, People's Dental Academy, Peoples University, Bhopal, Madhya Pradesh, India
}

\begin{abstract}
Aim: The purpose of this study was to evaluate the volumetric bone loss during osteotomy using CBCT immediately after placement of BOI (Basal Osseo-integrated Implant) \& Crestal implants followed by immediate loading.

Material \& Methods: The study included 20 patients reporting to the Outpatient department of Oral and Maxillofacial Surgery. The patients were randomly allotted to two groups. Group A $(n=10)$ received BOI implant and Group B $(n=10)$ received Crestal implants in maxillary \& mandibular anterior region. Volumetric analysis was performed with the post-operative radiological examination using cone bean computed tomography (CBCT).

Results: The mean volumetric bone loss between Triple Disc BOI \& Crestal Implant was $46.91 \& 115.55 \mathrm{~mm}^{3}$ respectively.

Conclusion: This study has shown that in patients with atrophied ridges disc implant can be used without any other augmentation procedure whereas in patients with ideal ridges conventional root form implant gives better esthetic \& functional results.
\end{abstract}

\section{Introduction}

Dental implants are gaining popularity, as tooth loss is a major problem due to disease or by any form of injury or trauma. Modern dental implantology developed out of the landmark studies of bone healing and regeneration conducted in the 1950s and 1960s by Swedish Orthopaedic surgeon P. I. Brånemark [1]. This therapy is based on the discovery that titanium can be successfully fused with bone when osteoblasts grow on and into the rough surface of the implanted titanium. This forms a structural and functional connection between the healthy bone and the placed implant. A variation on the implant procedure is the implant-supported bridge, or implant-supported denture [2-6].

Dental implants are considered as a preferred choice for prosthetic rehabilitation over conventional dentures. In the past years, various studies were performed to improve the design, material and technique for implants. The surface characteristics determine the longevity of the dental implants. There are various types of implant systems such as Conventional implants/ Crestal Implants, Mini Implants, Basal Osseointegrated Implants (BOI), routinely used in clinical practice.

Whenever the Conventional/ Crestal implants are placed in any of the maxillary or mandibular alveolar bone, if the bone is in good health than only the treatment outcome and rate of survival of implant is good enough. But in patients with long standing edentulism disuse atrophy may occur leading to alveolar bone resorption. These patients when taken up for implant rehabilitation have more susceptibility to undergo pathologic changes due to reduction in vascularity due to removal of more of cancellous part of bone.

Primarily, it is osseofixation which holds the implant in place to let it osseointegrate in functionless period of 3-4 months. So, for gaining initial strength of fixation the amount of residual bone will play a very important key role to handle stresses due to fixture and bone remodelling.

Biomechanical influences play an important role in the longevity of bone around implants. Forces on the implants during mastication transferred and lead to stresses in bone surrounding the implants. Too much stresses can lead to bone resorption, which eventually causes loosening of the implant [7]

The anterior teeth are an important factor in dental and facial esthetics [8]. At this time, in the anterior region they are difficult for both stabilization of the implant fixture and aesthetics of the restoration because they have narrower alveolar ridge and thinner cortical bone than in the posterior region $[9,10]$. In addition, the thickness of the

${ }^{*}$ Correspondence to: Ajay K Pillai, Professor \& HOD, Department of Oral \& Maxillofacial Surgery, People's Dental Academy, Peoples University, Bhopal, Madhya Pradesh, India, E-mail: drajaypillaiomfs@gmail.com

Key words: Volumetric Bone loss, Basal Implant, Crestal implant, CBCT

Received: June 05, 2019; Accepted: June 17, 2019; Published: June 20, 2019 
cortical bone has a larger influence on the initial stabilization than the length of the implant fixture in an edentulous region. Therefore, information on the cortical and cancellous bone thickness in the labial and lingual sides, especially the anterior part, is the key to successful dental implantation [11].

In this study, we have compared amount of bone loss in mandibular \& maxillary anterior region that occurred during implant placement using two different systems of implants. One group of patients received Triple Disc BOI implant and the other group received Crestal Implant.

\section{Materials and method}

The study included 20 patients reporting to the Outpatient department of Oral and Maxillofacial Surgery. The patients were randomly allotted to 2 groups. Group A $(n=10)$ received BOI implant (4T 5/7 H4 DISKOS ${ }^{-}$T4) and Group B $(n=10)$ received Crestal implants $(3.5 \times 13 \mathrm{~mm}$ Conventional Root Form Implant) and PostOsteotomy implant site preparation for each implant has been evaluated for volumetric bone loss using Sirona Orthphos SL CBCT machine.

The inclusion criteria for this study are patients having normal / atrophied ridges, D1 - D4 bone density, partially edentulous in anterior region of maxilla and mandible, healthy periodontium. The exclusion criteria are patients having osseous/periodontal pathology, systemic illness, Patients undergoing Radiotherapy/Chemotherapy/ Bisphosphonate therapy, Suspected adverse effect on patient's general health post-implant placement.

\section{Procedure}

The Implant placement procedure was performed under Local Anesthesia (LA) for both the groups. A single qualified surgeon for all the patients of both the groups placed the implant. A meticulous treatment planning was done before the surgery for all the patients and the implant size was determined according to the requirement. Pre-operative findings of all the patients were documented. The study included patients receiving implants in the mandibular \& maxillary anterior region in both the groups. Standard protocols were followed under aseptic condition. LA was administered using LOX $2 \%(1: 2$, 00,000 Adrenaline) to achieve nerve block and to aid in hemostasis. A crestal incision with bilateral releasing incision was placed in the site and the mucoperiosteal flap was reflected using a periosteal elevator. The osteotomy procedure for both the groups was different as both the implants had variable external surface.

\section{Osteotomy for BOI implant placement}

Basal implants may only be placed after a crestal flap has been reflected longitudinally to the jaw bone. A full thickness mucoperiostel flap was liberally dislodged and well secured to avoid any contact with rotating instrument. It is usually inserted longitudinally or obliquely.

The placement of BOI implants requires two types of osteotomies:

\section{1) Vertical osteotomy 2) Horizontal osteotomy}

During vertical Osteotomy, the first osteotomy was performed with vertical cutter of diameter of $1.6 \& 1.9 \mathrm{~mm}$ using airotor handpiece. Following the vertical osteotomy a horizontal Osteotomy was done with a horizontal /combination cutters of desired diameter i.e. $5 \mathrm{~mm}$ (ICT5N).

After Vertical and Horizontal osteotomy, the implant was inserted through a lateral access using a dosed hammer style strokes on the implant's base plate. It is essential that osteotomy extends into buccal and lingual / palatal cortex for better implant primary stability (Figures $1-5)$.

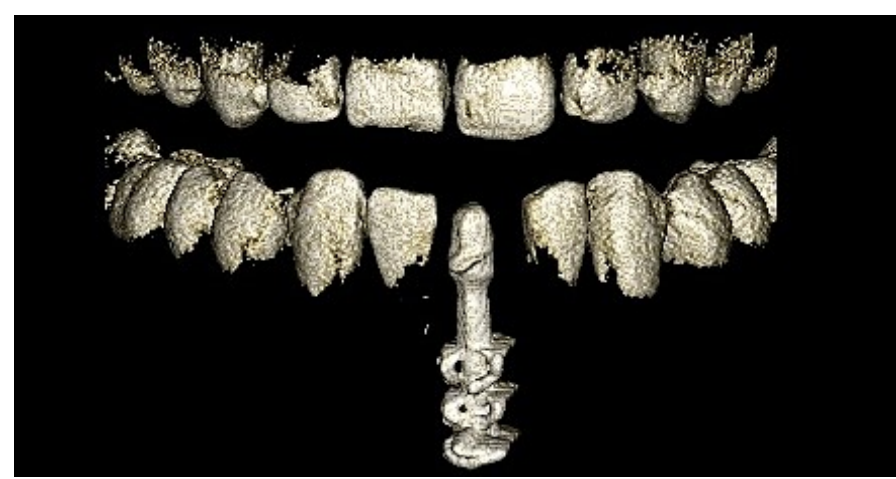

Figure 1: CBCT Image showing Triple Disc BOI Implant, Frontal View

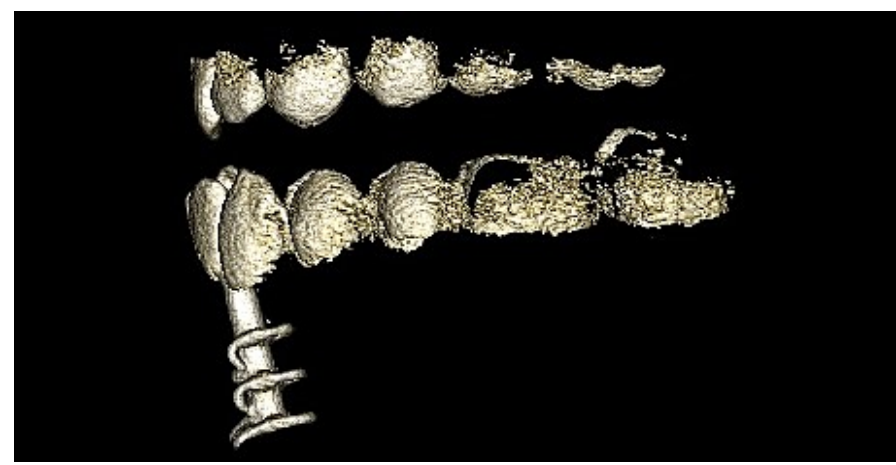

Figure 2: CBCT Image showing Triple Disc BOI Implant, Lateral View

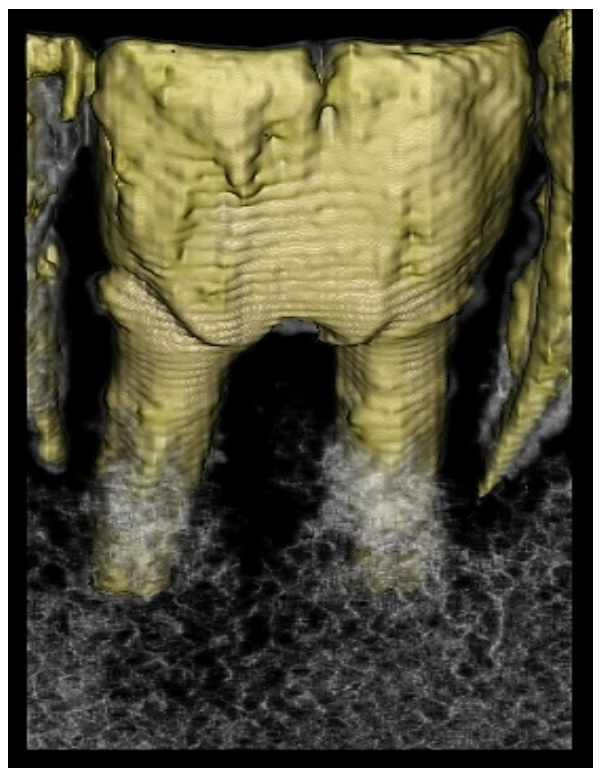

Figure 3: CBCT Image showing Crestal Implant, Frontal View

\section{Osteotomy for crestal implant placement}

After raising the full thickness mucoperiosteal flap, the osteotomy commenced with the placement of a punch cut using $2 \mathrm{~mm}$ pilot drill at low speed ( $45 \mathrm{rpm}$ at $50 \mathrm{Ncm}$ torque). The angulation was checked with the paralleling pin clinically, correction of discrepancy, if any, was performed at a later stage. Further osteotomy was carried out with the implant drill to the desired depth required for the implant placement. In Type I bone, it may be necessary to refine the osteotomy with the final size drill of the implant at extremely low speed $(30 \mathrm{rpm}$ at 45 


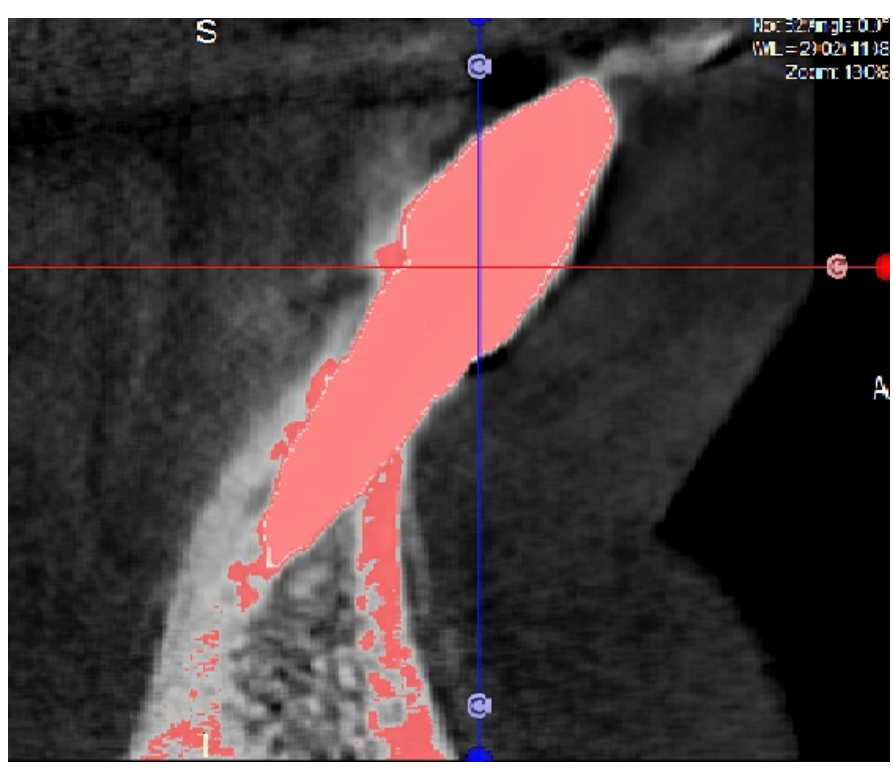

Figure 4: CBCT Image showing Crestal Implant, Lateral View

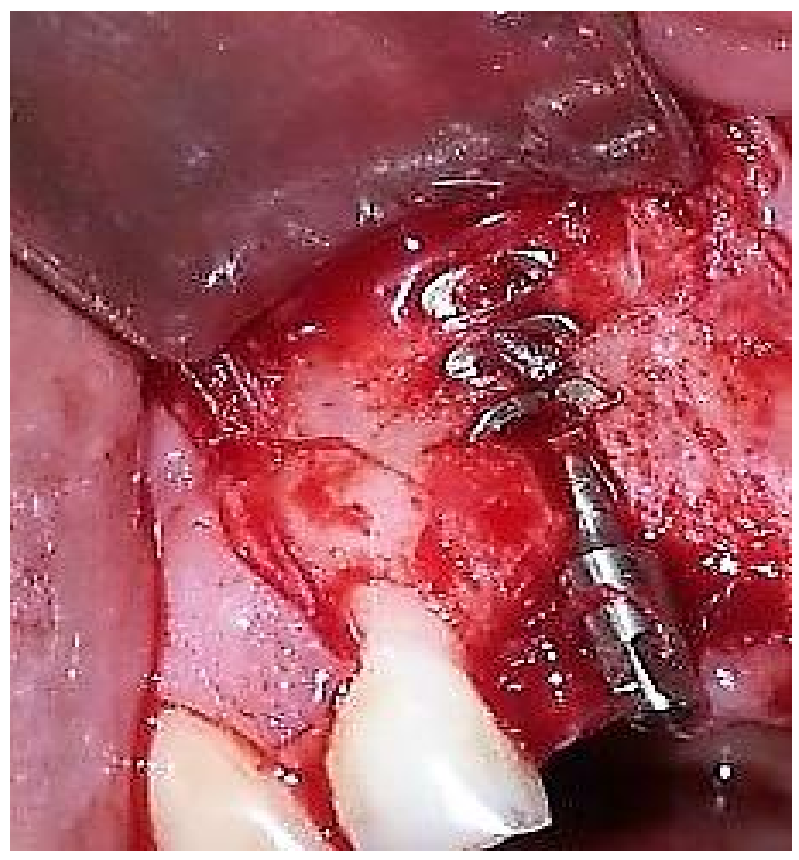

Figure 5: Intraoral image showing Triple Disc BOI Implant.

$\mathrm{Ncm}$ ). In type III and IV bone the implant can be safely tapped into the osteotomy using the rotary instrument or manually with a ratchet.

The patients were under Anti-biotic and Analgesic cover for 5 days followed by suture removal on the $7^{\text {th }}$ day Post-operatively.

\section{Statistical analysis}

Mean, standard deviation (SD), minimum and maximum values of volumetric bone loss in two implant systems were calculated. ShapiroWilk test showed that volumetric bone loss in two implant systems followed normal distribution. Hence parametric test, unpaired t-test was applied for data analysis. P value $<0.05$ was considered statistically significant. Data analyses were performed using version 21.0 of the Statistical Package for Social Sciences (IBM Corporation, Armonk, New York, USA).

\section{Results}

Table 1 and Graph 1 show comparison of volumetric bone loss in two implant systems. Mean \pm SD of volumetric bone loss in Group 1 (BOI implant) and Group 2 (Crestal implant) were $46.91 \pm 0.51 \mathrm{~mm}^{3}$ and $115.55 \pm 6.10 \mathrm{~mm}^{3}$, respectively. Minimum and maximum values of volumetric bone loss in Group 1 (BOI implant) were $46.02 \mathrm{~mm}^{3}$ and $47.81 \mathrm{~mm}^{3}$ and; in Group 2 (Crestal implant) were $108.23 \mathrm{~mm}^{3}$ and $125.07 \mathrm{~mm}^{3}$. Unpaired t-test showed that mean volumetric bone loss in Crestal implant system was significantly higher than BOI implant system $(\mathrm{t}=-34.459, P<0.001)$.

Table 2 shows Mean, standard deviation (SD), minimum and maximum values of volumetric bone loss in two implant systems were calculated. Shapiro-Wilk test showed that volumetric bone loss in two implant systems followed normal distribution. Hence parametric test, unpaired t-test was applied for data analysis. $\mathrm{P}$ value $<0.05$ was considered statistically significant.

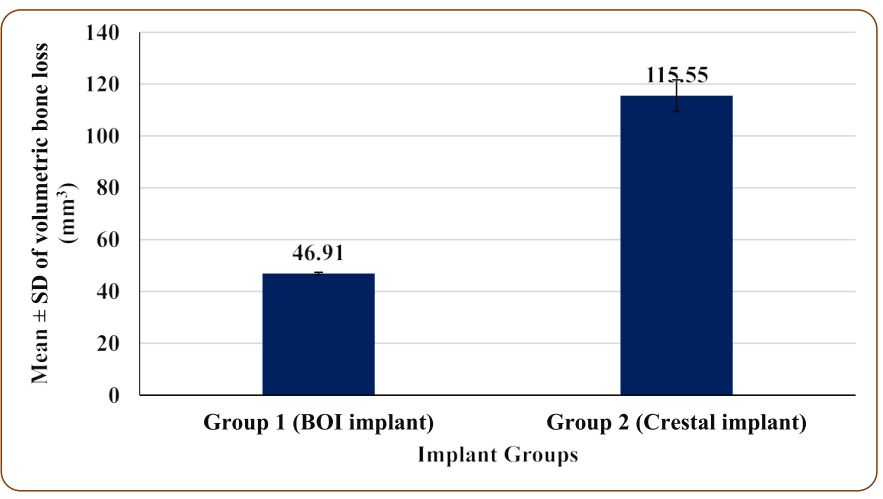

Graph 1. Mean and standard deviation of volumetric bone loss in two implant systems

Table 1: Shows comparison of volumetric bone loss in two implant systems. Mean volumetric bone loss in Crestal implant system was significantly higher than BOI implant system $(\mathrm{t}=-34.459, P<0.001)$

\begin{tabular}{|c|c|c|}
\hline S.No & $\begin{array}{c}\text { Group 1 } \\
\text { *Volumetric Bone Loss in } \\
\text { Triple Disc BOI Implant 4T } \\
\text { 5/7 H4 DISKOS }{ }^{\circledR} \text { T4 } \\
\left(\text { In mm }^{3}\right)\end{array}$ & $\begin{array}{c}\text { Group } 2 \\
\text { *Volumetric Bone Loss in } \\
\text { Conventional Root Form Implant } \\
\text { Conventional Root Form Implant } \\
\text { 3.5x13 } \mathbf{~ m m ~}\left(\text { In } \mathbf{~ m m}^{3}\right)\end{array}$ \\
\hline 1 & 46.02 & 125.07 \\
\hline 2 & 47.81 & 120.12 \\
\hline 3 & 47.35 & 117.85 \\
\hline 4 & 46.76 & 108.56 \\
\hline 5 & 46.85 & 122.28 \\
\hline 6 & 47.21 & 118.64 \\
\hline 7 & 46.56 & 108.23 \\
\hline 8 & 47.22 & 114.56 \\
\hline 9 & 46.87 & 109.64 \\
\hline 10 & 46.49 & 110.56 \\
\hline Total Bone Loss & 469.14 & 1155.51 \\
\hline Mean Bone Loss & 46.91 & 115.55 \\
\hline
\end{tabular}

*Volumetric bone loss evaluated using Sirona Orthphos SL CBCT machine.

Table 2: Comparison of volumetric bone loss in two implant systems

\begin{tabular}{|c|c|c|}
\hline \multirow{2}{*}{ Implant groups } & \multicolumn{2}{|c|}{ Volumetric bone loss $\left.\mathbf{( m m}^{\mathbf{3}}\right)$} \\
\cline { 2 - 3 } & Mean \pm SD & Min-Max \\
\hline Group 1 (BOI implant, $\mathrm{n}=10)$ & $46.91 \pm 0.51$ & $46.02-47.81$ \\
\hline Group 2 $($ Crestal implant, $\mathrm{n}=10)$ & $115.55 \pm 6.10$ & $108.23-125.07$ \\
\hline Unpaired t-test & \multicolumn{2}{c}{$=-34.459, \mathrm{P}=0.000(<0.001)$} \\
& \multicolumn{2}{|c|}{ Very high Significance } \\
\hline
\end{tabular}




\section{Discussion}

Past decades have shown a paradigm shift from a surgically-driven to a prosthetically-driven approach in dental implant therapy [12]. To improve the overall success of implant therapy with possible reduction in surgical and postoperative implant complications, implantologists should have three-dimensional (3D) information of bone volume and topography prior to implant placement [13].

Pre-surgical assessment of implant site by imaging technique thus allows for the accurate assessment of the amount of bone volume available, bone density, and proximity to anatomical structures. CBCT is the most preferred option from all other radiological tools for implant dentistry as it provides greater measurement accuracy when compared to two-dimensional (2D) imaging, while utilizing much lower doses of radiation [14-16]. Loubele et al. reported that both CBCT and CT yielded submillimeter accuracy for linear measurements on an ex vivo specimen for implant measurements [17].

During this study, bone volume loss was identified after osteotomy was performed, prior to implant placement in every case using CBCT imaging, which suggest amount of bone volume displaced to place implant. In other words, more the bone lost lesser the stability gained viz. less bone is present to counter the masticatory and remodelling stresses. Which clinically manifests as implant loosening \& thus failure is inevitable.

Stephen Ihde $[18,19]$ reported that when bone height decreases to low levels such as 3-5 $\mathrm{mm}$ then only two effective options are either BOI or BCS implant with wide threads. In such cases, crestal implants can only be placed after additional surgical procedure like bone augmentation through only bone grafting, alveolar distraction or sinus lift procedures etc.

Osteoporosis, which literally means "porous bone", is a disease which effects the bone that reduces the density and quality of bone. As the bones become more porous and fragile, the risk of fracture increases. In Cases of osteoporosis \& osteopenia where bone volume \& bone density is compromised, use of basal implants gives potential conservative approach for implant placement, as it causes less bone volume loss during drilling, thus conserving the already deficient bone as well as better stability due to bi-cortical engagement [20,21].

Ihde S, Ihde A (2010) [22] mentioned that this is apparent because basal implants engage cortical bone, which has higher density as compared to alveolar bone where crestal implants are placed. Thereby basal implants have more primary stability because of engagement of $1^{\text {st }}, 2^{\text {nd }} \& 3^{\text {rd }}$ cortical of basal bones.

Volumetric loss also can be interpreted in terms of sacrificed bone during implant placement i.e., if there is increased amount of bone loss then it subsequently affects the healing phase and reduction in stability of the implant.

Ihde S, Ihde A (2015) [23] mentioned that crestal implants have most of their parts in spongious bone area which slowly osseointegrate by active biological process of bone remodelling or through process of 'Gap Jumping', thus showing lesser primary stability. In basal implants, osseointegration due to bone remodeling is minimized thus instead of final osseointegration the effect of initial osseofixation produces more primary stability in basal implant.

Clinically, the criterion of a minimal buccal bone width of $2 \mathrm{~mm}$ to maintain a stable buccal bony wall is valid only for a limited number of sites in the anterior maxilla. The data obtained suggested that in the majority of extraction sites in the anterior maxilla, thin $(\leq 1 \mathrm{~mm})$ buccal walls were present. This, in turn, means that in most clinical situations encountered, augmentation procedures needed to achieve adequate bony contours around the implant [24].

Therefore, it is apparent that in anterior maxilla most of the cases have deficient thickness of buccal cortical, which can be further compromised by osteotomy needed for placement of crestal implant. Thus, mandating the use of bone augmentation and grafting techniques during crestal implant placement, which further enhances the time, morbidity \& cost of treatment. This disadvantage can be obviated by use of basal implant, which needs minimal osteotomy in comparison to crestal implant.

\section{Conclusion}

This study has shown that there is increased bone loss in patients receiving crestal implant, i.e. Conventional Root Form Implant implants as compared to patients receiving Triple Disc BOI implant for given dimensions while rehabilitation of anterior maxilla $\&$ mandible.

As the diameter of crestal implant increases the volume of bone which has to be osteotomized, increases proportionately. Whereas in basal implant the dimension of vertical osteotomy is fixed, i.e. 1.6-1.9 $\mathrm{mm}$ diameter and the width of horizontal osteotomy is also constant, i.e. $0.3 \mathrm{~mm}$ thickness. The size of disk comes in variable anteroposterior and mesio-distal dimensions, larger disk can be used as per the availability of bone, which further enhances the primary stability of implant and safe distance from vital structures. This also obviates that the larger the disk size, larger will be the area of distribution of masticatory load among buccal or lingual / palatal cortices.

It is also concluded from above study that the use of basal implant gives more conservative approach for stable implant rehabilitation.

\section{References}

1. Reddy S. Essentials of clinical periodontology and periodontics, 2006 First Edition, Jaypee Brothers Medical Publishers (P) Ltd.

2. Tomasi C, Wennström JL, Berglundh T (2008) Longevity of teeth and implants: A systematic review. J Oral Rehabil 35(Suppl 1):23-32.

3. Jung RE, Pjetursson BE, Glauser R (2008) A systematic review of the 5-year survival and complication rates of implant-supported single crowns. Clin Oral Implants Res 19(2):119-130.

4. Iacono VJ, Cochran DL (2007) State of the science on implant dentistry: a workshop developed using an evidence-based approach. Int J Oral Maxillofac Implants 22(Suppl):7-10

5. Ong CT, Ivanovski S, Needleman IG (2008) Systematic review of implant outcomes in treated periodontitis subjects. J Clin Periodontol 35(5):438-462.

6. Misch CE, Perel ML, Wang HL (2008) Implant success, survival, and failure: The International Congress of Oral Implantologists (ICOI) Pisa Consensus Conference. Implant Dent 17(1):5-15.

7. Meijer HJA, Kuiper JH, Starmans FJM, Bosman F. Stress distribution around dental implants: influence of superstructure, length of implants and height of mandible. $J$ Prosthet Dent 68:96-102.

8. Ku JE, Yang HS, Yun KD. A morphometric analysis of maxillary central incisor on the basis of facial appearance in Korea. $J$ Adv Prosthodont 4:13-17.

9. Bernard JP, Schatz JP, Christou P, Belser U, Kiliaridis S (2004) Long-term vertical changes of the anterior maxillary teeth adjacent to single implants in young and mature adults. A retrospective study. J Clin Periodontol 31:1024-1028.

10. Buser D, Martin W, Belser UC (2004) Optimizing esthetics for implant restorations in the anterior maxilla: anatomic and surgical considerations. Int J Oral Maxillofac Implants 19:43-61.

11. Miyamoto I, Tsuboi Y, Wada E, Suwa H, Iizuka T (2005) Influence of cortical bone thickness and implant length on implant stability at the time of surgery-clinical, prospective, biomechanical, and imaging study. Bone 37:776-780.

12. Tetradis S, Anstey P, Graff-Radford S (2010) Cone beam computed tomography in the diagnosis of dental disease. J Calif Dent Assoc 38(1):27-32. 
13. Tyndall DA, Price JB, Tetradis S, Ganz SD, Hildebolt C, Scarfe WC (2012) American Academy of Oral and Maxillofacial Radiology. Position statement of the American Academy of Oral and Maxillofacial Radiology on selection criteria for the use of radiology in dental implantology with emphasis on cone beam computed tomography. Oral Surg Oral Med Oral Pathol Oral Radiol 113(6):817-826.

14. Macleod I, Heath N (2008) Cone-beam computed tomography (CBCT) in dental practice. Dent Update 35(9):590-592,594.

15. Howerton WB, Mora MA (2008) Advancements in digital imaging: what is new and on the horizon? J Am Dent Assoc 139:20S-24S.

16. Dreiseidler T, Mischkowski RA, Neugebauer J, Ritter L, Zöller JE (2009) Comparison of cone-beam imaging with orthopantomography and computerized tomography for assessment in presurgical implant dentistry. Int J Oral Maxillofac Implants 24(2):216225.

17. Tischler M (2008) In-office cone beam computerized tomography: technology review and clinical examples. Dent Today 27(6):102,104,106.
18. Loubele M, Van Assche N, Carpentier K (2008) Comparative localized linear accuracy of small-field cone-beam CT and multislice CT for alveolar bone measurements. Oral Surg Oral Med Oral Pathol Oral Radiol Endod 105(4):512-518.

19. Ihde S (2005) Principles of BOI, 1 Edn. Heidelberg: Springer.

20. Ihde S (2009) CMF. Impl Dir.

21. Richards JB, Leslie WD, Joseph L (2007) Changes to osteoporosis prevalence according to method of risk assessment. J Bone Miner Res 22:228-234.

22. Krishnan V (2015) Volumetric analysis of mandible for dental implants in cbct images. International Journal of Recent Advances in Multidisciplinary Research 2(1):01550160 .

23. Ihde S, Ihde A (2010) Immediate loading: Guideline to successful implantology,2nd Edition, Implant Foundation Publ.

24. Huynh-Ba G, Pjetursson BE, Sanz M, Cecchinato D, Ferrus J, Lindhe J, Lang NP (2010) Analysis of the socket bone wall dimensions in the upper maxilla in relation to immediate implant placement. Clin Oral Impl Res. 21:37-42.

Copyright: (C2019 Pillai AK. This is an open-access article distributed under the terms of the Creative Commons Attribution License, which permits unrestricted use, distribution, and reproduction in any medium, provided the original author and source are credited. 